\title{
PERANCANGAN DAN IMPLEMENTASI SISTEM E-COMMERCE PADA UMKM BATIK DI KABUPATEN JOMBANG
}

\author{
Renny Sari Dewi*1, Oki Anita Candra Dewi ${ }^{2}$, Rizky Noviasri ${ }^{3}$ \\ ${ }^{1}$ Program Studi Sistem Informasi, Universitas Internasional Semen Indonesia \\ ${ }^{2}$ Program Studi Teknik Logistik, Universitas Internasional Semen Indonesia \\ ${ }^{3}$ Program Studi Desain Komunikasi Visual, Universitas Internasional Semen Indonesia \\ *E-mail: renny.rsd@gmail.com
}

\begin{abstract}
The rapid development of information technology (IT) is directly proportional to the increase of the middle-class economy segment. As one of the original products of the Indonesian people, batik and all its variety is not spared from the impact of IT development. To introduce one of the various types of batik craft typical of Jombang Regency, the author partnered with UD Litabena and UD Batik Colet as micro, small-medium enterprise (SME) to participate in introducing the region's distinctive batik craft. Therefore, the implementation of the community partnership program aims to design and implement e-supply chain in the form of e-commerce which is useful to facilitate SME to sell Jombang's batik craft products in all circles in Indonesia. There are 5 stages in the implementation of this program, including surveying the business process of making Jombang batik craft, determining the superior motives of MSMEs, designing system requirements, developing systems, and implementing web-based e-commerce systems. The conclusion obtained is, the system was designed by Enterprise Architect software, and the webbased e-commerce was built with the WooCommerce plugin.
\end{abstract}

Keywords-e-supply chain, e-commerce, batikcraft, jombang

Abstrak

Pesatnya perkembangan teknologi informasi (TI) berbanding lurus dengan peningkatan ekonomi di kalangan menengah. Sebagai salah satu produk asli bangsa Indonesia, batik dan segala ragamnya tidak luput dari dampak perkembangan TI. Untuk mengenalkan salah satu ragam batik khas Kabupaten Jombang, penulis bermitra dengan UD Litabena dan UD Batik Colet sebagai pelaku usaha mikro, kecil, dan menengah (UMKM) untuk turut mengenalkan batik khas daerah tersebut. Maka dari itu, pelaksanaan program kemitraan masyarakat ini bertujuan untuk merancang dan mengimplementasikan rantai pasok elektronik (e-supply chain) dalam bentuk ecommerce yang berguna memudahkan UMKM menjualkan produk batik jombang di seluruh kalangan di Indonesia. Terdapat 5 tahapan dalam pelaksanaan program ini, diantaranya survei proses bisnis pembuatan batik jombang, penentuan motif unggulan UMKM, perancangan kebutuhan sistem, pembangunan sistem, dan implementasi sistem e-commerce berbasis web. Kesimpulan yang didapatkan adalah, sistem dirancang dengan bantuan software Enterprise Architect, e-commerce berbasis web dibangun dengan plugin WooCommerce.

Kata kunci-rantai pasok elektronik, e-commerce, batik, jombang

\section{PENDAHULUAN}

$\mathrm{B}$ atik khas Kabupaten Jombang-selanjutnya disebut dengan batik jombang, merupakan salah satu ragam batik Indonesia yang diproduksi oleh pelaku usaha mikro, kecil, dan menengah (UMKM) dan tergabung dalam Asosiasi Pengrajin Batik Jombang (APBJ) sejak 2015. Pada pelaksanaan program kemitraan masyarakat ini, penulis melibatkan dua mitra pengrajin batik jombang yaitu UD Litabena dan UD Batik Colet. 
Tahun 2015, Kabupaten Jombang melalui Dewan Kreatif Nasional Daerah (Dekranasda), telah memegang paten motif batik Menara Ringin Contong yang merupakan khas dari daerah tersebut. Batik jombang saat ini telah dikenal oleh masyarakat Provinsi Jawa Timur. Namun secara strategis, sebagai produk anak bangsa, batik jombang sejatinya dapat dikenal luas hingga ke mancanegara.

Sejalan dengan misi pemerintah dalam menggalakkan nasionalisme terhadap produkproduk UMKM tanah air, saat ini sedang gencarnya penjualan berbasis daring. Sangat banyak online marketplace yang tengah eksis di seluruh kalangan masyarakat. Hal ini seharusnya ditanggapi bijak oleh pelaku UMKM untuk mendongkrak bisnis kerajinan batik di wilayah Kabupaten Jombang.

Bahkan yang tak kalah menarik, pengusaha jasa kurir juga mulai berinvestasi di desa guna memudahkan pelaku UMKM yang ingin turutserta. Hal tersebut diharapkan dapat berdampak secara makro yaitu meningkatkan pendapatan per kapita penduduk di desa yang memiliki usaha di bidang kerajinan batik jombang. Seperti halnya yang telah ada, untuk memajukan pengrajin batik lokal salah satunya dengan mengimplementasikan e-commerce [1] [2].

Beberapa hal di atas menjadi latar belakang penulis untuk mengangkat batik jombang agar dikenal masyarakat luas melalui perancangan dan implementasi sistem e-commerce berbasis web.

Manfaat adanya program kemitraan masyarakat ini antara lain:

- bagi pelaku UMKM adalah produk kerajinan batik jombang dapat dikenal lebih luas hingga mancanegara,

- bagi pemerintah adalah ekonomi makro yang mampu menyejahterakan pelaku UMKM di bidang kerajinan batik,

- bagi akademisi adalah tentunya pengalaman membangun jaringan penta-helix, yang salah satunya adalah pengusaha/praktisi.

\section{METODE}

Penulis melakukan program kemitraan masyarakat ini kepada 2 mitra batik di Kabupaten Jombang. Adapun profil singkat kedua mitra terangkum pada Tabel 1.

Tabel 1 Profil Singkat Mitra

\begin{tabular}{lll}
\hline Deskripsi & UD Litabena & UD Batik Colet \\
\hline Tempat & Kec. Diwek, Kab. Jombang & Kec. Diwek, Kab. Jombang \\
Jumlah pengrajin batik & 10 orang & 15 orang \\
Tahun produksi & 2012 & 2016 \\
\hline
\end{tabular}

Metode yang digunakan dalam melaksanakan program kemitraan masyarakat ini dibagi menjadi 4 tahapan seperti penjelasan berikut:

1) Survei Proses Bisnis UMKM Batik Jombang

Survei proses bisnis pelaku UMKM batik jombang dilakukan kepada kedua mitra yaitu UD Litabena dan UD Batik Colet.

2) Penentuan Motif Khas UMKM

Tahap penentuan motif ini dipilih berdasarkan observasi lapangan dan wawancara mitra.

3) Perancangan Kebutuhan Sistem E-Commerce

Untuk perancangan kebutuhan sistem e-commerce, penulis menggunakan pendekatan Unified Modeling Language (UML) sederhana, yaitu pembuatan diagram kasus penggunaan (use case diagram).

4) Pembangunan Sistem E-Commerce

Menurut terminologinya, e-commerce merupakan penyebaran, pembelian, penjualan, pemasaran barang/jasa yang dilakukan oleh beberapa pihak terkait (konsumen dan penjual) 
melalui sistem elektronik seperti internet $w w w$ (World Wide Web), atau jaringan komputer lainnya [3]. E-commerce seringkali melibatkan transaksi data, baik dana elektronik, sistem manajemen inventori otomatis, hingga sistem rekapitulasi data otomatis.

Pembangunan sistem e-commerce yaitu dengan melakukan instalasi dan konfigurasi pada Content Management Systems Wordpress yang telah tertanam dengan plugin WooCommerce. Justifikasi pemilihan WooCommerce sebagai platform e-commerce adalah kepopulerannya dan kemudahan dalam pengoperasian. Di sisi lain, aspek user friendly dan kustomisasi yang cukup sederhana turut menjadi pertimbangan penting lainnya.

Namun penulis menyadari terbatasnya waktu pengembangan dan implementasi, maka proses pengujian sistem e-commerce tidak dilakukan. Hal inilah yang menjadi batasan pelaksanaan program kemitraan masyarakat ini. Sejatinya, serangkaian pengujian dan evaluasi ini bertujuan untuk menemukan celah pada fungsi yang tidak tepat/hilang, kesalahan antarmuka, kesalahan struktur data, hingga kesalahan perilaku saat mengakses sistem [4].

\section{HASIL DAN PEMBAHASAN}

Berdasarkan 4 tahapan pada metode di atas, maka hasil dari pelaksanaan program kemitraan masyarakat adalah sebagai berikut:

1) Survei Proses Bisnis UMKM Batik Jombang

Survei proses bisnis pelaku UMKM batik jombang dilakukan kepada kedua mitra yaitu UD Litabena dan UD Batik Colet. Perhatikan Gambar 1, 2, dan 3 berikut ini.

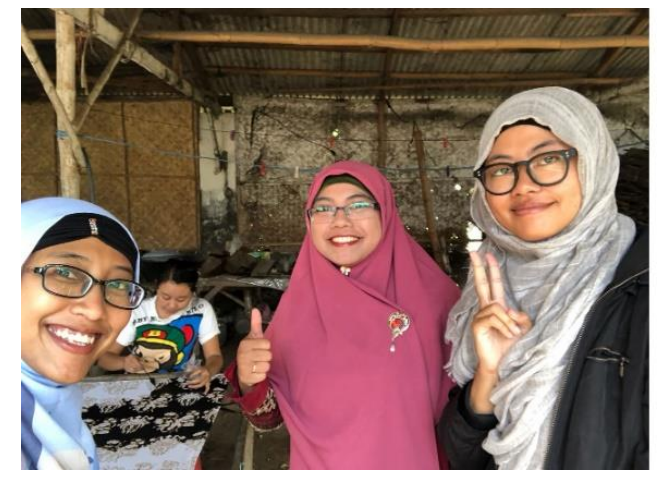

Gambar 1 Survey proses bisnis pembuatan batik dari hulu ke hilir

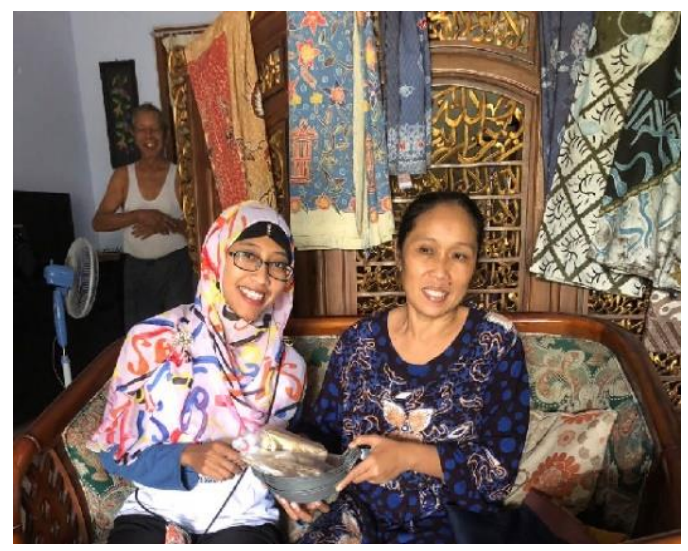

Gambar 2 Kunjungan tim PKM ke salah satu mitra UMKM batik jombang UD Litabena 


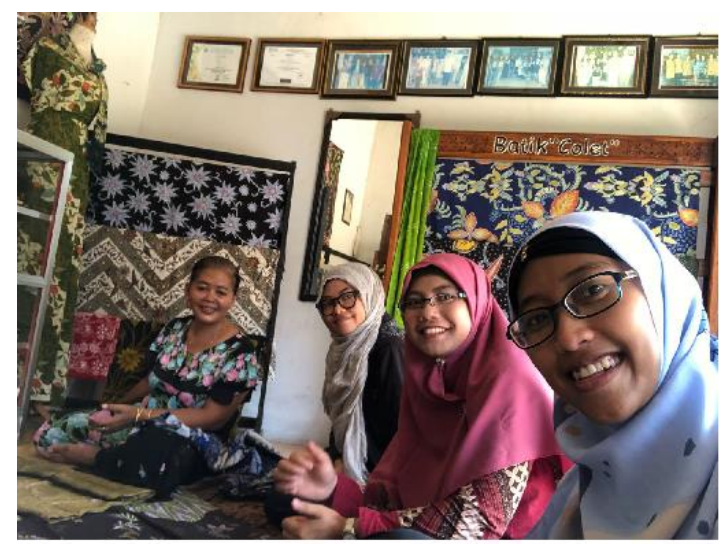

Gambar 3 Kunjungan tim PKM ke salah satu mitra UMKM batik jombang UD Batik Colet

2) Penentuan Motif Khas UMKM kedua mitra.

Motif yang tersaji pada Gambar 4 adalah beberapa contoh batik yang dihasilkan oleh
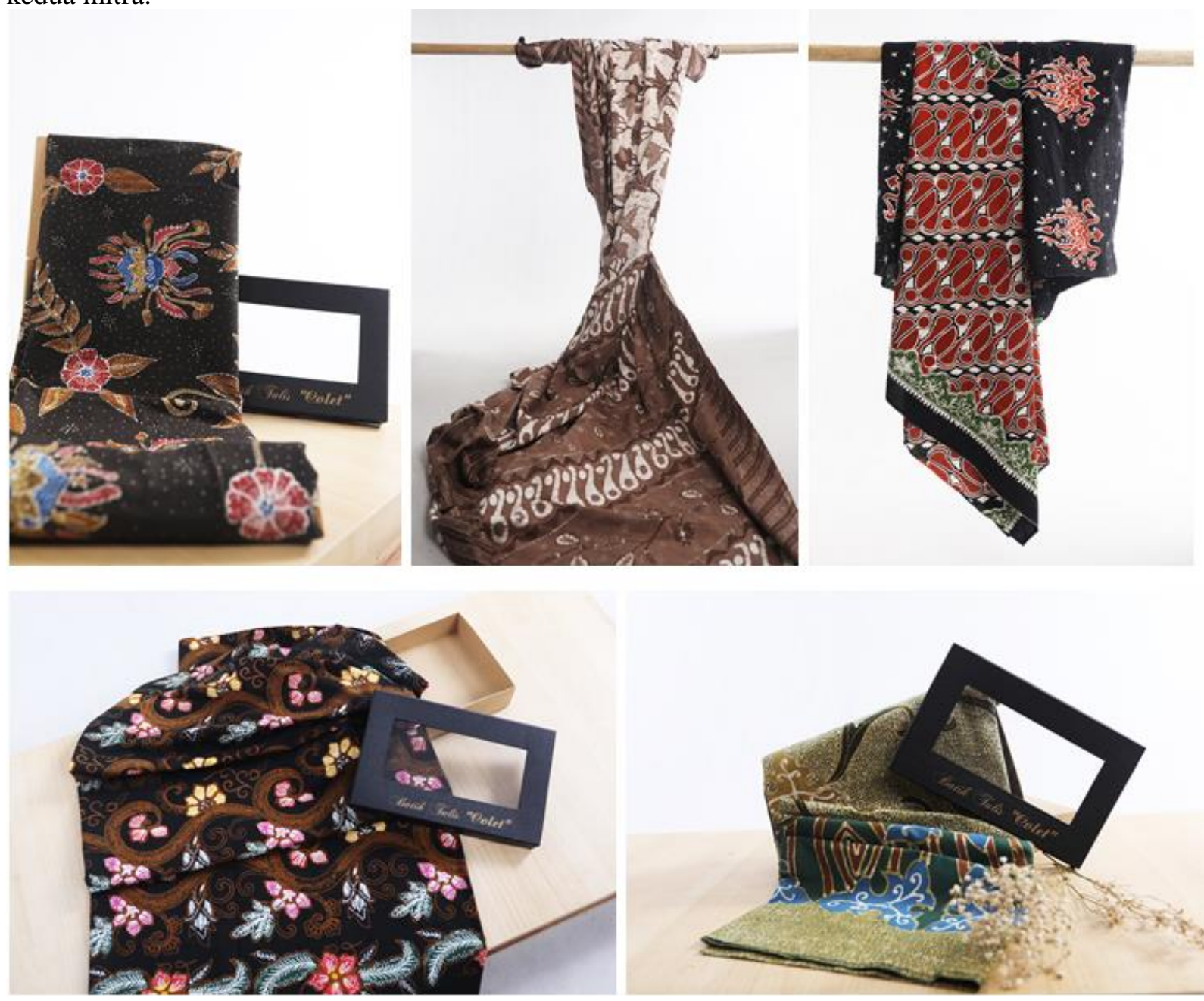

Gambar 4 Motif Unggulan UMKM Batik di Kabupaten Jombang

3) Perancangan Kebutuhan Sistem E-Commerce

Pada tahapan perancangan kebutuhan sistem e-commerce ini, penulis mengadopsi kerangka kerja Unified Modeling Language (UML) sederhana, yaitu diagram kasus 
penggunaan (use case diagram). Gambar 5 merepresentasikan mitra/pemilik usaha batik dapat mengelola katalog yang berisi motif dan stok yang tersedia.

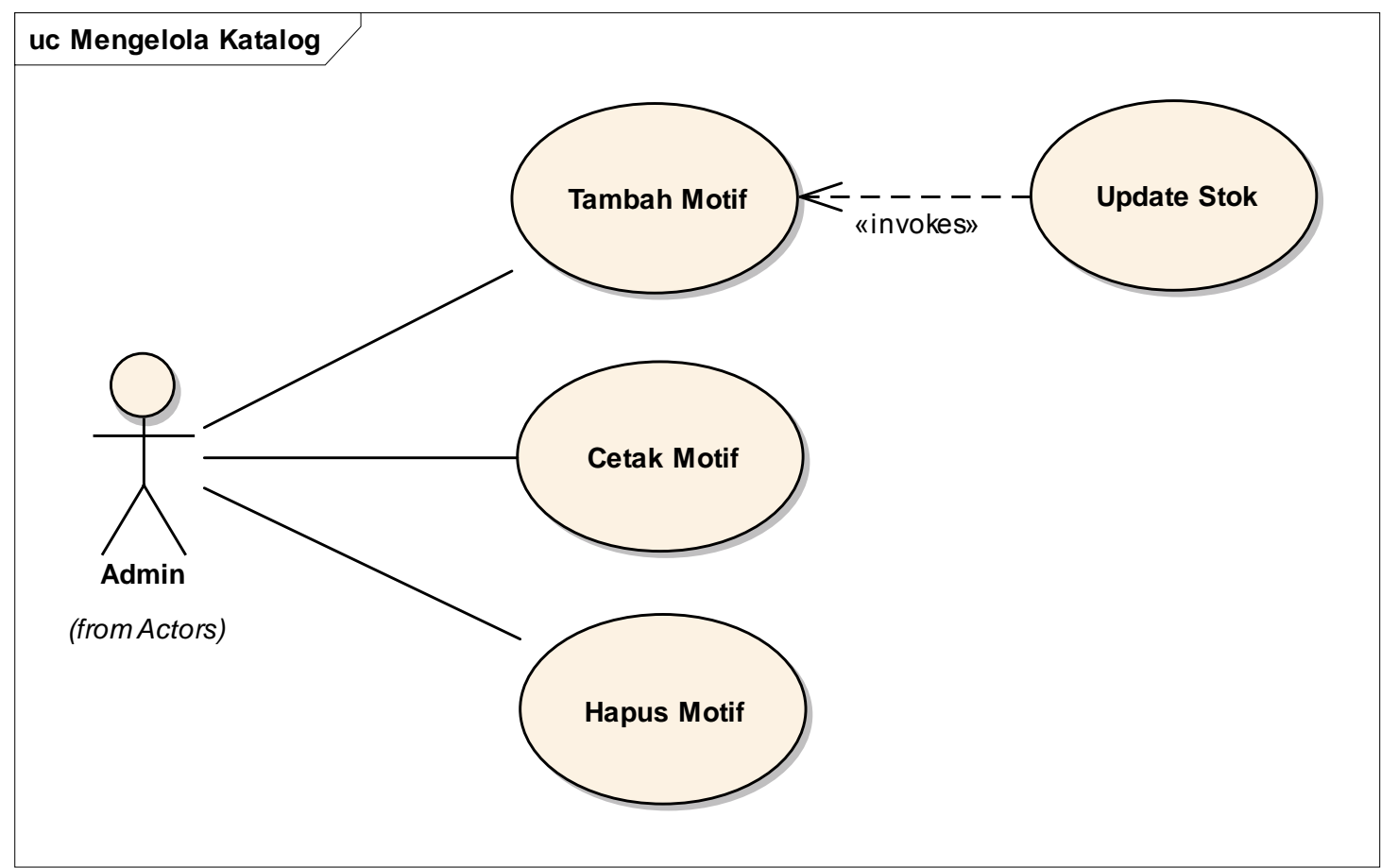

Gambar 5 Use Case Diagram untuk Mengelola Katalog

Pada Gambar 6 dan 7, penulis membuat use case diagram untuk mengelola pesanan yang saling terkoneksi dengan mengelola pembayaran. Berdasarkan use case diagram yang ada, maka terlihat bahwa sistem e-commerce belum terintegrasi dengan penelusuran pengiriman barang.

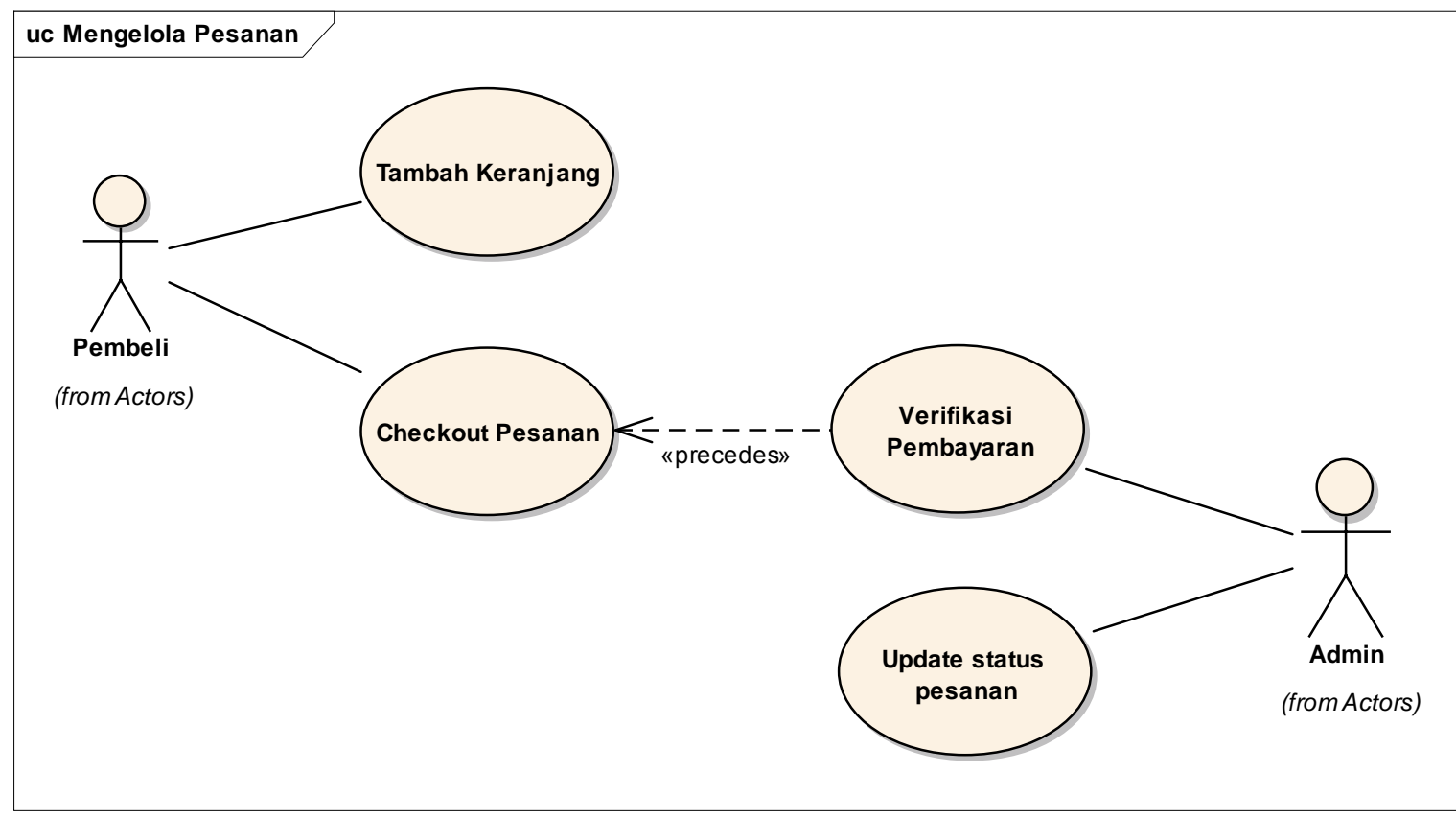

Gambar 6 Use Case Diagram untuk Mengelola Pesanan 


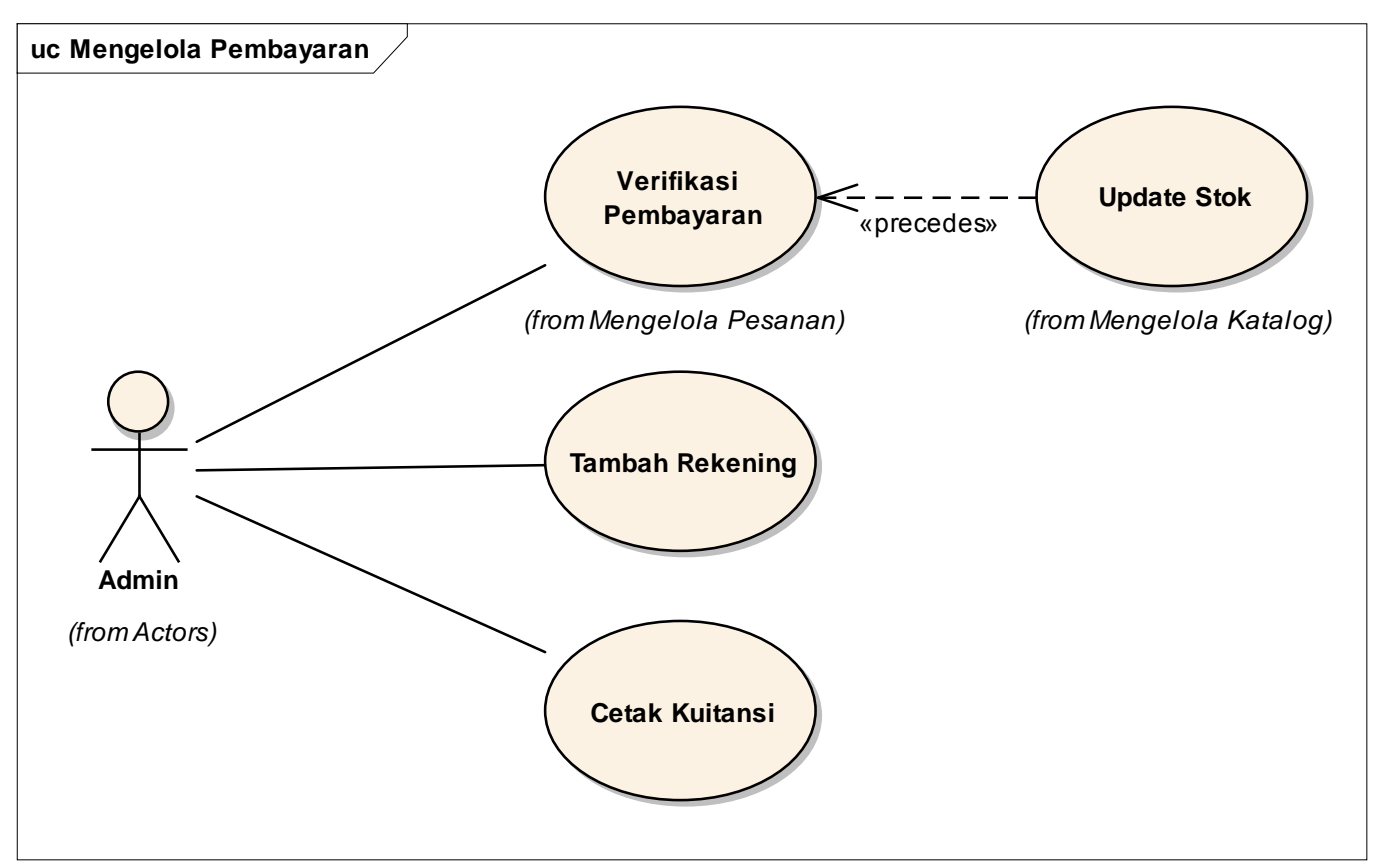

Gambar 7 Use Case Diagram untuk Mengelola Pembayaran

Dari Gambar 5, 6, dan 7, maka dapat diketahui bahwa operasional online marketplace batik jombang berjumlah 10 kasus penggunaan (use case). Kesepuluh use case ini terdiri dari:

1. Tambah Motif

2. Update Stok

3. Cetak Motif

4. Hapus Motif

5. Tambah Keranjang

6. Checkout Pesanan

7. Verifikasi Pembayaran

8. Update Status Pesanan

9. Tambah Rekening

10. Cetak Kuitansi

Keseluruhan use case ini telah dikonfirmasi dengan mitra batik jombang yaitu pengelola UD Litabena dan UD Batik Colet.

4) Pembangunan Sistem E-Commerce

Dalam pembangunan sistem e-commerce, penulis memiliki alasan yang melatarbelakangi pemilihan plugin WooCommerce untuk dijadikan online marketplace batik jombang. Beberapa alasannya adalah:

- Populer di kalangan software developer dalam hal kemudahan melakukan kustomisasi layout

- Antarmuka yang ramah pengguna dan modern. Hal ini dapat dilihat pada Gambar 8. 

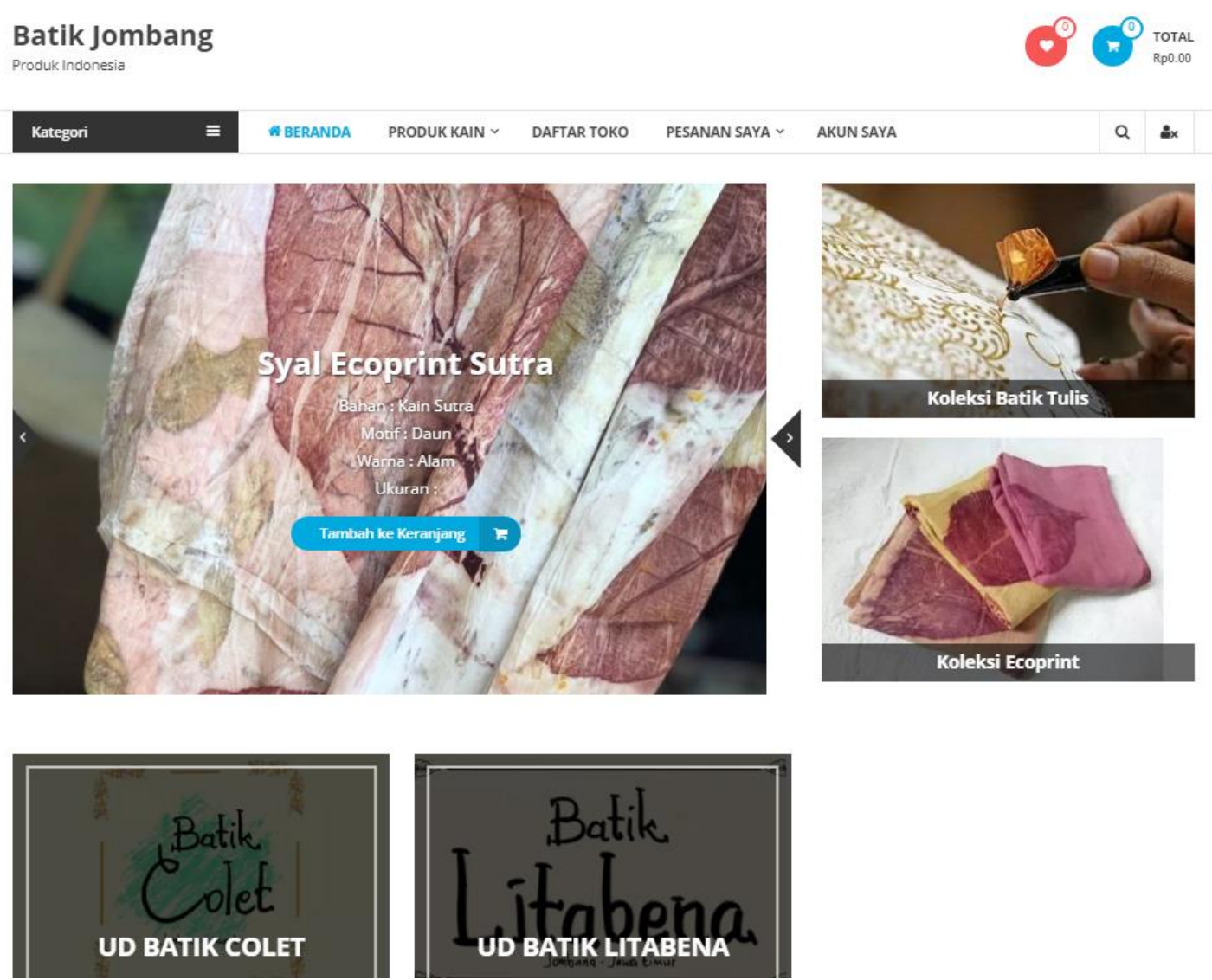

Gambar 8 Tampilan $e$-Commerce yang Telah Dibangun

\section{KESIMPULAN}

Dari penjelasan di atas, maka dapat disimpulkan beberapa hal berikut ini:

1) Terdapat 2 mitra yang terlibat dalam program kemitraan masyarakat, yaitu UD Litabena dan UD Batik Colet. Keduanya merupakan pengrajin UMKM di Kabupaten Jombang.

2) Empat tahapan yang dilaksanakan penulis untuk dapat menerapkan e-commerce pada UMKM batik Kabupaten Jombang, yaitu survei proses bisnis, penentuan motif khas UMKM, perancangan kebutuhan sistem e-commerce, dan pembangunan sistem ecommerce.

3) Terdapat 12 kasus penggunaan (use case) untuk mengoperasikan online marketplace batik jombang.

\section{SARAN}

Hasil pelaksanaan program kemitraan masyarakat yang berupa laman e-commerce saat ini berada di fase pengembangan dan implementasi. Sedangkan untuk fase selanjutnya adalah pengujian dan evaluasi. Pengujian yang dimaksud meliputi kotak hitam (black-box) dan kotak putih (white-box). Oleh karena itu, kedua fase akan dilakukan oleh peneliti di tahun berikutnya. 


\section{UCAPAN TERIMA KASIH}

Penulis mengucapkan terima kasih kepada Direktorat Jendral Penguatan Riset dan Pengabdian Kepada Masyarakat (DRPM) Kementerian Riset, Teknologi, dan Pendidikan Tinggi atas pendanaan yang diberikan. Selain itu, ucapan terima kasih juga disampaikan kepada Lembaga Penelitian dan Pengabdian Kepada Masyarakat (LPPM) Universitas Internasional Semen Indonesia (UISI) yang telah mendukung, mengarahkan, dan memfasilitasi secara moril.

\section{DAFTAR PUSTAKA}

[1] F. Wiyani and N. A. Prabowo, "Peningkatan Daya Saing Bisnis Batik Kahuripan Melalui Sistem Penjualan Berbasis E-Commerce," in Seruni-Seminar Riset Unggulan Nasional Inoformatika dan Komputer, 2013, vol. 2, no. 1.

[2] F. Amin, R. Soelistijadi, and A. Priyambodo, "Aplikasi E-Commerce Sentra Batik di Kota Semarang Sebagai Salah Satu Upaya Media Promosi dan Transaksi Secara Online," Din. Teknol. Inf., vol. 17, no. 1, 2012.

[3] A. Saefullah, S. Santoso, and others, "Analisa dan Perancangan Sistem Informasi Penjualan Online (E-Commerce) Pada CV Selaras Batik," 2014.

[4] T. Wahyuningrum and D. D. Januarita, "Implementasi dan Pengujian Web E-commerce untuk Produk Unggulan Desa,” J. Komput. Terap., vol. 1, no. 1, pp. 57-66, 2015. 